\title{
NASA Cryocooler Technology Developments and Goals to Achieve Zero Boil-Off and to Liquefy Cryogenic Propellants for Space Exploration
}

D. Plachta, J. Stephens, W. Johnson, NASA

M. Zagarola and D. Deserranno (Creare, LLC).

\begin{abstract}
NASA's interest in human exploration of Mars has driven it to invest in $20 \mathrm{~K}$ cryocooler technology to achieve zero boil-off of liquid hydrogen and 90K cryocooler technology to achieve zero boil-off liquid oxygen or liquid methane as well as to liquefy oxygen or methane that is produced on the surface of Mars. These investments have demonstrated efficiency progress, mass reductions, and integration insights. A history of the application of cryocooler technology to zero boil-off propellant storage is presented. A trade space on distributed cooling is shown, along with the progress of reverse turbo-Brayton cycle cryocoolers, where the specific power and specific mass have dropped, decreasing the mass and power of these cryocoolers. Additionally, the cryocooler technology advancements of recuperators and compressors are described. Finally, NASA's development ideas with respect to zero boil-off technology are discussed.
\end{abstract}

Key Words: multi-layer insulation, reverse turbo-Brayton cycle cryocooler, zero boil-off, cryogenic propellant storage

\section{Background}

NASA is working to improve the utilization of high-specific-impulse propellant combinations such as liquid hydrogen, oxygen, and methane $\left(\mathrm{LH}_{2}, \mathrm{LO}_{2}\right.$, and $\left.\mathrm{LCH}_{4}\right)$. These efforts are prerequisite to achieving a human presence on the surface of Mars and to facilitating an expanded presence across the solar system. Realization of these goals underlies the need to store and manage high-energy propellants for extended periods of time while under conditions of microgravity. NASA therefore continues to devote human and capital resources to technology development in support of extending the useful duration of cryogens in space propulsion systems, orbit transfer stages, and related applications.

Volumetric considerations require that hydrogen, oxygen, and methane propellants be stored as liquids at extremely low temperatures. This constitutes an engineering challenge in light of anticipated natural environments in space. Heat radiated to a spacecraft from the Sun and other celestial bodies in proximity to the spacecraft (such as Earth, the Moon, and Mars), in addition to heat conducted to the storage tanks from other sources on the spacecraft, cause the cryogens to pressurize or boil off (i.e., change state from liquid to gas). This venting results in less propellant remaining available for propulsion. Because mission loiter periods are projected to be up to 1300 days long (Ref. 1), vented losses will be substantial. To offset these losses, the stage would need to accommodate excess propellant, substantially increasing the mass of the stage. Alternatively, NASA could use thick-walled propellant tanks in conjunction with greater working pressures, but the additional mass of the tanks could be prohibitive for certain missions. The mass and 
power of active refrigeration using space cryocoolers, first developed for the space telescope industry, is not prohibitive and reduces the size and mass of the cryogenic upper stage when compared to venting the cryogen over long periods of time. There are two types of cryocoolers considered - the Stirling cycle, which uses piston compression and expansion of helium, and the reverse turbo-Brayton cycle (RTBC), which utilizes steady flow of turbomachinery.

Given that NASA's interests in this extends back to the 1990's, the focus of this paper is to highlight how the zero boil-off (ZBO) concept has evolved over the years and to discuss the future plans to improve the concept.

\section{History of Testing}

The advancement of flight cryocooler technology in the 1980's and early 1990's spawned the prospects of zero boil-off cryogenic propellant storage and in the mid-1990s, various concepts were defined to achieve zero boil-off (ZBO) in-space propellant storage. The first ZBO testing focused on the in-space application and was conducted at the NASA Glenn Research Center (Ref. 2) in 1998, followed by testing at the NASA Marshall Space Flight Center (Ref. 3) in 2001. The common objective was to assess the feasibility of ZBO concepts using readily available components. The first proof of concept incorporated a cryocooler at the top of a liquid hydrogen $\left(\mathrm{LH}_{2}\right)$ propellant tank (Fig. 1) and a copper shield within the multilayer insulation (MLI). While this test demonstrated a steady decline in tank pressure due to the heat removed by the cryocooler, the thermal gradient between the fluid and the cryocooler was $8 \mathrm{~K}$, causing a significant loss in heat "lift" (or an increase in power). Also, this test was not flight-like because it used fluid buoyancy to convey heat to the cryocooler and an industrial cryocooler was used. The test at Marshall Space Flight Center was more flight-like insofar as $\mathrm{LH}_{2}$ was pumped through an actively cooled bypass loop (see heat exchanger that coupled the cryocooler to the $\mathrm{LH}_{2}$ in Fig. 2) to facilitate heat extraction. While $\mathrm{ZBO}$ was easily achieved, the heat leak of the bypass loop and the heat from the continuous pump operation were inefficiencies in that zero boil-off approach.

A test at Glenn in 2003 (Ref. 4) used a flight cryocooler design to achieve ZBO with liquid nitrogen $\left(\mathrm{LN}_{2}\right)$, but again a high cryocooler-to-propellant thermal gradient $(6.9 \mathrm{~K}$ for a cryocooler placed adjacent to the tank) led to concerns about scaling the test results to large flight tanks, where greater distances between the cryocooler and tank are anticipated. Also noteworthy is the fact that a submerged mixer was used in conjunction with the cryocooler to control tank pressure. The mixer pump added heat to the tank fluid, like it did in the MSFC test, requiring an increase in the lift capacity of the cryocooler. Figure 3 shows a schematic of a modified configuration of the system tested, to represent a more efficient flight system. 

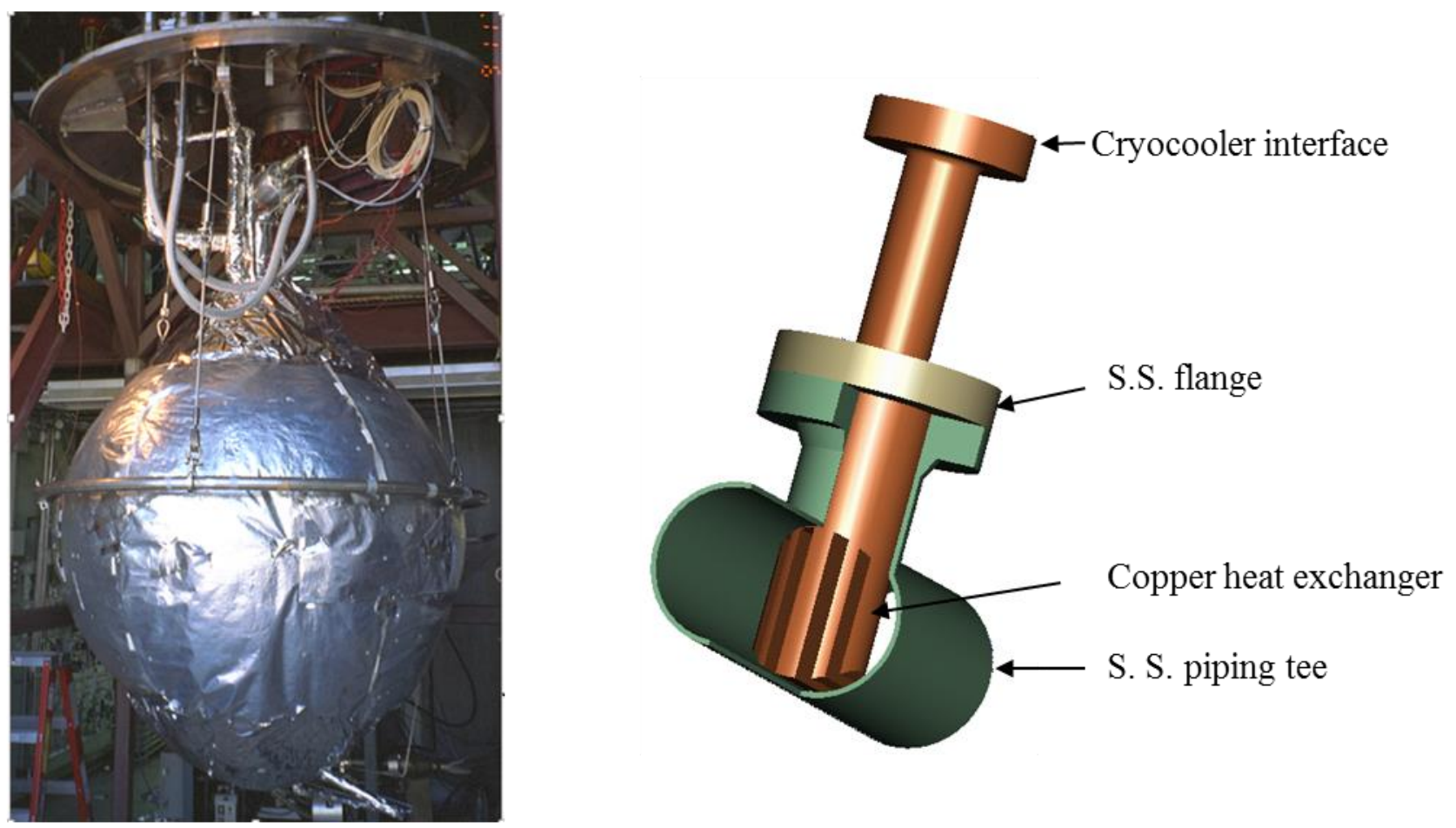

Figure 1. First LH2 ZBO test, 1998, NASA GRC.

Figure 2. MSFC LH2 ZBO test heat exchanger design.

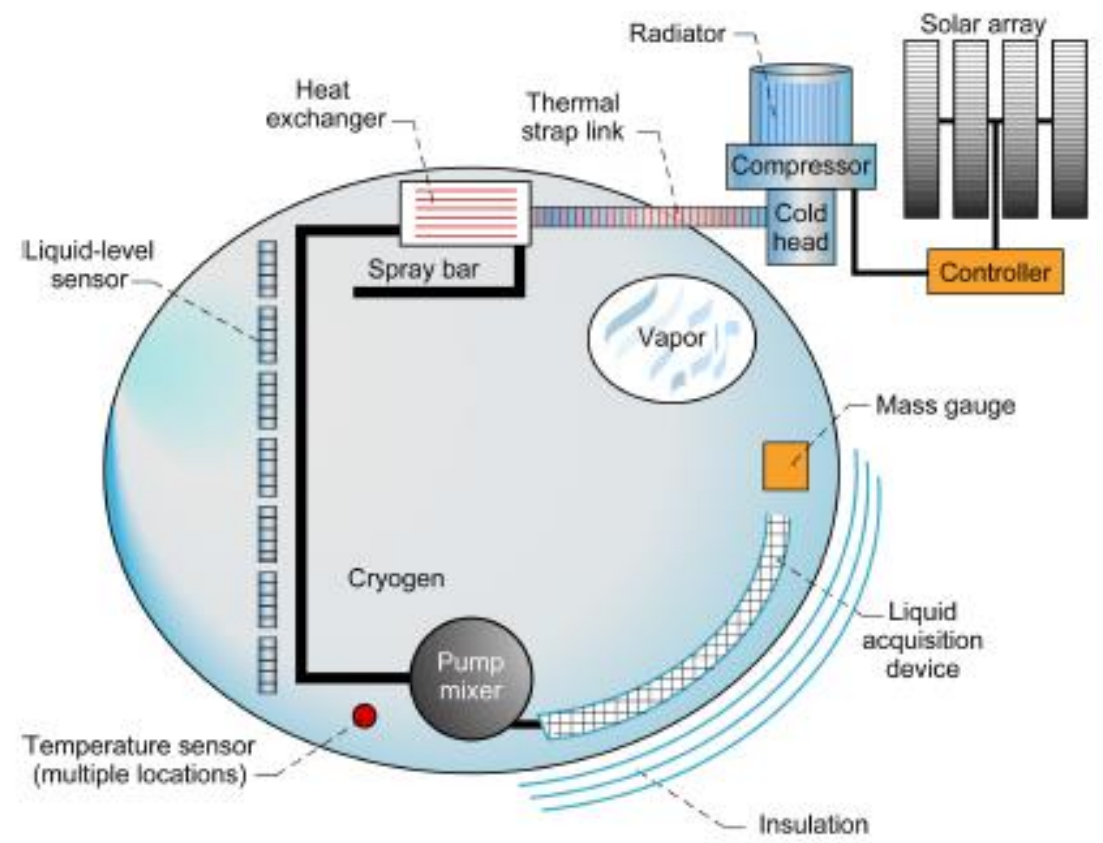

Figure 3.- Schematic of a flight configuration of the ZBO system under consideration in 2003.

Although each successive test series served a purpose, the ZBO approach based upon in-tank fluid cooling was set aside in search of a better system for integrating the cryocooler. Development work shifted focus in 2007, in support of a cryogenic depot study involving larger 
tanks. A concept (Ref. 5) was proposed to integrate the cryocooler via a circulated gas loop coupled to the exterior of the tank. This configuration allowed for heat removal at the tank wall and also by a cooled shield placed in the multi-layer insulation, to reduce tank heat. The shield could also be thermally coupled to thermal straps to pre-cool tank penetrations. This concept is known as the Cryogenic Boil-Off Reduction System (CBRS) and more informally, as broad area or distributed cooling. The required heat exchanger analyses (Ref. 6) and component testing (Ref. 7) were performed at the NASA Ames Research Center. Relationships involving the temperature rise in the gas stream and the temperature profile in the foil were determined and empirically validated. Following component development tests, a system test on a broad-areacooled (BAC) shield (see Figure 4) was performed at Ball Aerospace Technology Corporation, under the Innovative Partnership Program (Ref. 8). Test results were in agreement with analytical predictions, demonstrating a high shield thermal effectiveness. Testing also showed minimal temperature variation among the three parallel coolant loops that compose the shield, despite the tubes being $120^{\circ}$ apart on a 500 liter tank. This showed that the concept was not sensitive to slight flow balance issues in the cooling loop. Additionally, since the shield temperature gradients predicted from conduction was less than expected, it was apparent that the MLI on both sides of the shield was instrumental in homogenizing the cooling effect of the discrete tube passes.

\section{Cryocooler Integration Trade Study}

In 2011, an engineering feasibility trade study (Ref. 9) was conducted to identify, evaluate, and compare options for cooling large surface areas of propellant tanks, building off the previous

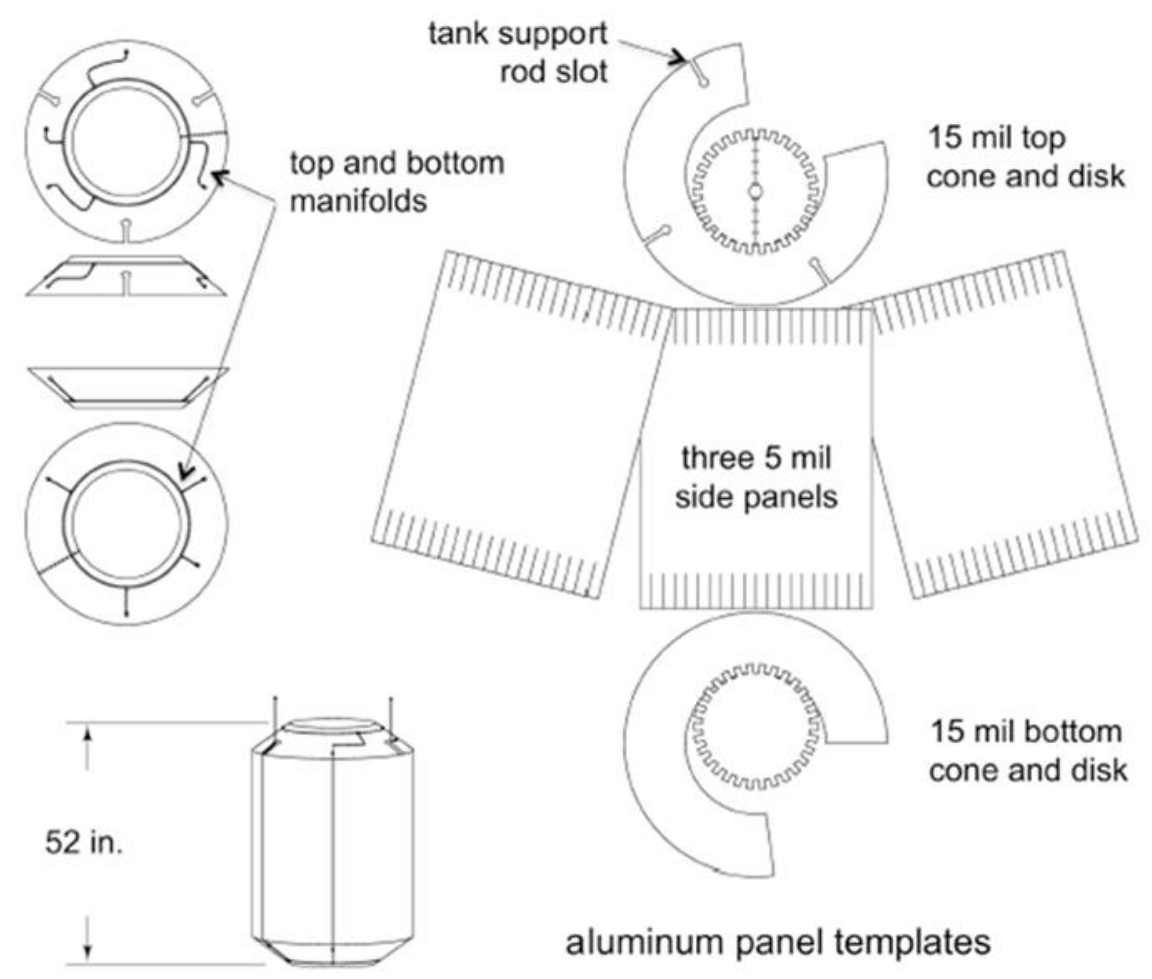

Figure 4. The broad area cooled shield, constructed from 1100 aluminum panels and cooled with three $1 / 4$ " tubes. 
distributed cooling investigations. This study included a survey of available flight rated or flight type cryocoolers, as well as a comprehensive study of circulating options for integrating the cryocooler with the propellant tank. Included with the cryocooler integration concept was the cooled shield approach previously tested for reducing boil-off. There were two requirements of the study; the first was that the chosen system be relevant and scalable to large in-space propellant tanks and the second was that the technology be readily available and within budget to facilitate ground-based testing of a flight-like system. The foregoing trade study therefore entailed a survey of commercially available hardware followed by an evaluation of implementation concepts. Evaluation of these concepts was specifically for a $90 \mathrm{~K}$ cryocooler system integrated with a propellant tank. Note in the following discussions, $90 \mathrm{~K}$ refers to a class of cryocoolers that would be relevant for integration with $\mathrm{LO}_{2}$, which has a boiling point at $95.6 \mathrm{~K}$ at $25 \mathrm{psi}$, and $\mathrm{LCH}_{4}$, which has a likewise boiling point of $118.4 \mathrm{~K}$. The $20 \mathrm{~K}$ cryocooler is for $\mathrm{LH}_{2}$ storage, which has a $22.3 \mathrm{~K}$ boiling point at 25 psi. Besides the cryocooler, the other component extensively investigated was the circulator.

Two types of cryocoolers were investigated. The first uses reverse turbo-Brayton-cycle (RTBC) cryocoolers wherein circulation of the working fluid directly cools the tank wall. The second uses a discrete cryocooler, such as a pulse-tube or Stirling-cycle cooler, coupled to a separate distribution loop that requires a circulator to move the working fluid through the cooling loop. The cryocoolers considered included models from Creare, Northrop Grumman, Sunpower, and Ball. A distinguishing characteristic of the pulse-tube and Stirling cycle coolers is their small cold fingers. For instance, the Sunpower model cold finger is only $19 \mathrm{~mm}$ wide, which is difficult to integrate with a tank that has $7 \mathrm{~m}^{2}$ of surface area. The RTBC cryocooler, on the other hand, has a built in circulator to distribute cooling effectively through a tubing network that can be close-coupled to the tank, which uses the same working fluid as the cryocooler, thus eliminating the need for a second fluid and the associated heat exchanger in the cooling system.

Table 1 identifies the manufacturers of the circulators considered in the course of the study as well as the respective circulator type and characteristics. One basis for comparison among circulators is the associated amount of heat added to the system. Not explicitly considered was the heat exchanger loss when integrating with the cold finger, which could be substantial. As its main result, the circulator survey found the lack of an available cold circulator, thus any extraneous circulation loop would require a warm circulator and a highly efficient recuperative heat exchanger. The only circulator identified with fairly low heat gain that did not need further development was the Creare Near Infrared Camera and Multi-Object Spectrometer (NICMOS) circulator. Given that this circulation was inherently available as part of the RTBC cryocooler, NASA procured the RBTC cryocooler from Creare.

TABLE 1.-CIRCULATOR CHARACTERISTICS 


\begin{tabular}{|c|c|c|c|c|c|c|c|c|c|}
\hline Manufacturer & $\begin{array}{c}\text { Mass, } \\
\mathrm{kg}\end{array}$ & $\mathrm{TRL}_{\mathrm{a}}$ & $\begin{array}{c}\text { Input } \\
\text { power } \\
, \\
\mathrm{W}\end{array}$ & $\begin{array}{l}\text { Heat } \\
\text { Leak } \\
\text { to } \\
\text { fluid, } \\
\text { W }\end{array}$ & Fluid & $\begin{array}{c}\text { Phase, } \\
\Phi\end{array}$ & $\begin{array}{c}\text { Motor } \\
\text { temp., } \\
\mathrm{K}\end{array}$ & $\begin{array}{c}\text { Flow, } \\
\mathrm{g} / \mathrm{s}\end{array}$ & $\begin{array}{c}\text { Press., } \\
\text { atm }\end{array}$ \\
\hline CryoZone Ciezo & N/A & 5 & N/A & 4 & $\mathrm{He}$ & $\begin{array}{l}\text { Gas } \\
\text { (cold) }\end{array}$ & 85 & 0.6 & 21 \\
\hline Sierra Lobo He blower & 1 & 4 & 0.28 & .14 & $\mathrm{He}$ & $\begin{array}{l}\text { Gas } \\
\text { (cold) }\end{array}$ & 85 & .57 & 20 \\
\hline $\begin{array}{l}\text { Creare NICMOS } \\
\text { circulator }\end{array}$ & 1 & 9 & .89 & .6 & $\mathrm{Ne}$ & $\begin{array}{l}\text { Gas } \\
\text { (cold) }\end{array}$ & 80 & .75 & 3 \\
\hline $\begin{array}{l}\text { CryoZone Noordenwind } \\
\text { CryoFan }\end{array}$ & $\mathrm{N} / \mathrm{A}$ & 5 & .6 & N/A & $\mathrm{He}$ & Gas (hot) & 300 & .57 & 21 \\
\hline $\begin{array}{l}\text { Aerojet He gas } \\
\text { circulator }\end{array}$ & 3.5 & 5 & 2.8 & 2.0 & $\mathrm{He}$ & $\begin{array}{l}\text { Gas } \\
\text { (cold) }\end{array}$ & 150 & .8 & 20 \\
\hline Barber-Nichols & N/A & 4 & 71 & 44.9 & $\mathrm{He}$ & $\begin{array}{l}\text { Gas } \\
\text { (cold) }\end{array}$ & 90 & 41.8 & 27 \\
\hline Sierra Lobo piston & 1 & 3 & .01 & .001 & $\mathrm{~N}_{2}$ & $\begin{array}{l}\text { Liquid } \\
(2-\Phi)\end{array}$ & 85 & .13 & 2 \\
\hline $\begin{array}{l}\text { Lawrence Lab bellows } \\
\text { linear }\end{array}$ & 4.5 & 3 & 16.5 & 5.0 & $\mathrm{He}$ & $\begin{array}{l}\text { Liquid } \\
(2-\Phi)\end{array}$ & 4.5 & 40 & 4 \\
\hline Mikrosysteme 2-phase & N/A & 4 & .1 & .0 & $\mathrm{Ar}$ & $\begin{array}{l}\text { Liquid } \\
(2-\Phi)\end{array}$ & 120 & .3 & 12 \\
\hline
\end{tabular}

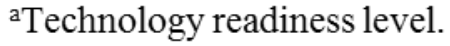

\section{Distributed Cooling Tests}

Following the trade study and the subsequent hardware development and integration into NASA Glenn Research Center's Small Multi-Purpose Research Facility, SMiRF, Reduced Boiloff (RBO) and ZBO tests were conducted. These efforts were recently published (Ref. 10, 11, and 12), so are just briefly discussed here. All tests were performed on a $1.2 \mathrm{~m}$ diameter, $1.4 \mathrm{~m}^{3}$ tank insulated with MLI and installed in a vacuum chamber with a cryoshroud surrounding the test article to simulate the vacuum and temperatures expected in low Earth orbit (see the test rig 
in Figure 5). The first two tests were $\mathrm{RBO}$ tests with $\mathrm{LH}_{2}$ propellant, utilizing a shield placed in the multi-layer insulation (MLI) and cooled by a 90K RTBC cryocooler. The integration of the cryocooler to the propellant tank MLI proved to be feasible (see schematic in Figure 6). The broad area cooled reduced the MLI heat by 55\%, a little less than expected. Because the temperature data indicated that the Lockheed equation (Ref. 13) used to model the MLI was not suitable in the 20-90 K temperature range, additional MLI investigations are needed to achieve the expected MLI temperature profile and to remove the heat projected by the pre-test model. Where the tank penetration cooling straps were coupled to the shield, the boil-off was reduced by $67 \%$. Between the cooling straps and the MLI cooling shield, the cryocooler system reduced propellant boil-off by $60 \%$. This is a substantial reduction in the $\mathrm{LH}_{2}$ tank heat accomplished with a $90 \mathrm{~K}$ cryocooler, which is much more efficient, requires less power, and is less costly than a $20 \mathrm{~K}$ cooler. Perhaps most importantly, it reduces the size of the $20 \mathrm{~K}$ cryocooler, which has a lower state of readiness than the $90 \mathrm{~K}$ cryocoolers.

The third test, a tube-on-tank ZBO application, was also successful. In this test, the cryocooler system temperature was adjusted to control tank pressure. The steady state ZBO condition occurred when both were balanced, which occurred with the net heat into and out of the tank close to zero. When the cryocooler power was increased, tank pressure decreased. When the cryocooler power was insufficient to remove the tank heat, tank pressure increased. A curve of pressure rise/decay rates for the various tests conducted vs. net tank heat, the cryocooler heat removed less the measured tank heat, is shown in Fig. 7. The model prediction shown is from a homogenous model, which assumes the fluid was fully mixed and isothermal. Given that the test data agreed closely with this model, it was apparent that the fluid behaved like it was fully mixed and de-stratified. Temperature data confirmed this. With the cryocooler off, the tank cryogenic fluid thermal gradient was $10.2 \mathrm{~K}$, from the bottom to the top of the tank. With the cryocooler on

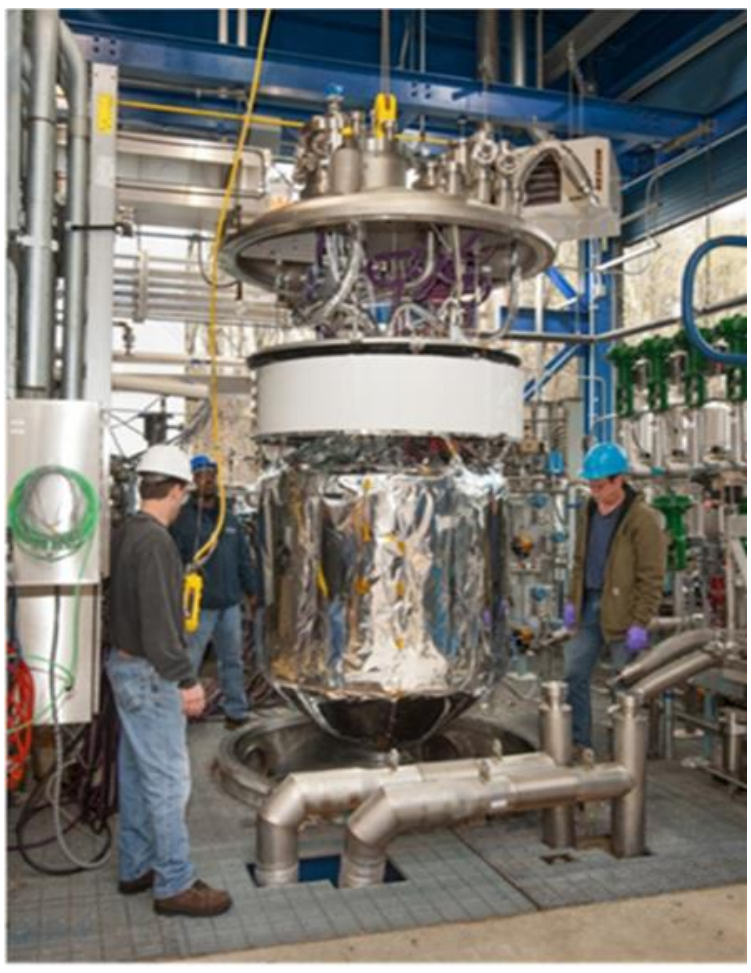

Figure 5. The NASA SMiRF test rig used in $\mathrm{RBO}$ and $\mathrm{ZBO}$ testing. 


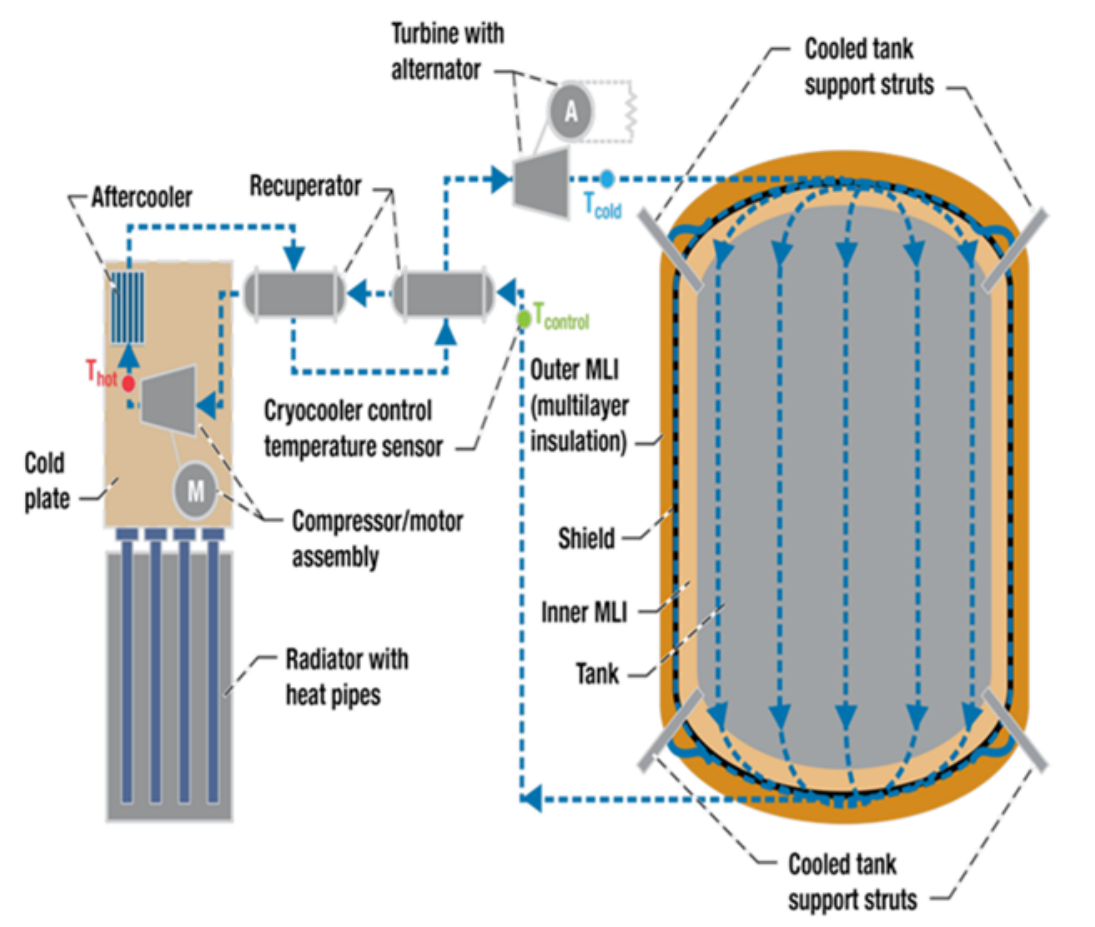

Figure 6. Schematic of the reverse turbo-Brayton cycle cryocooler

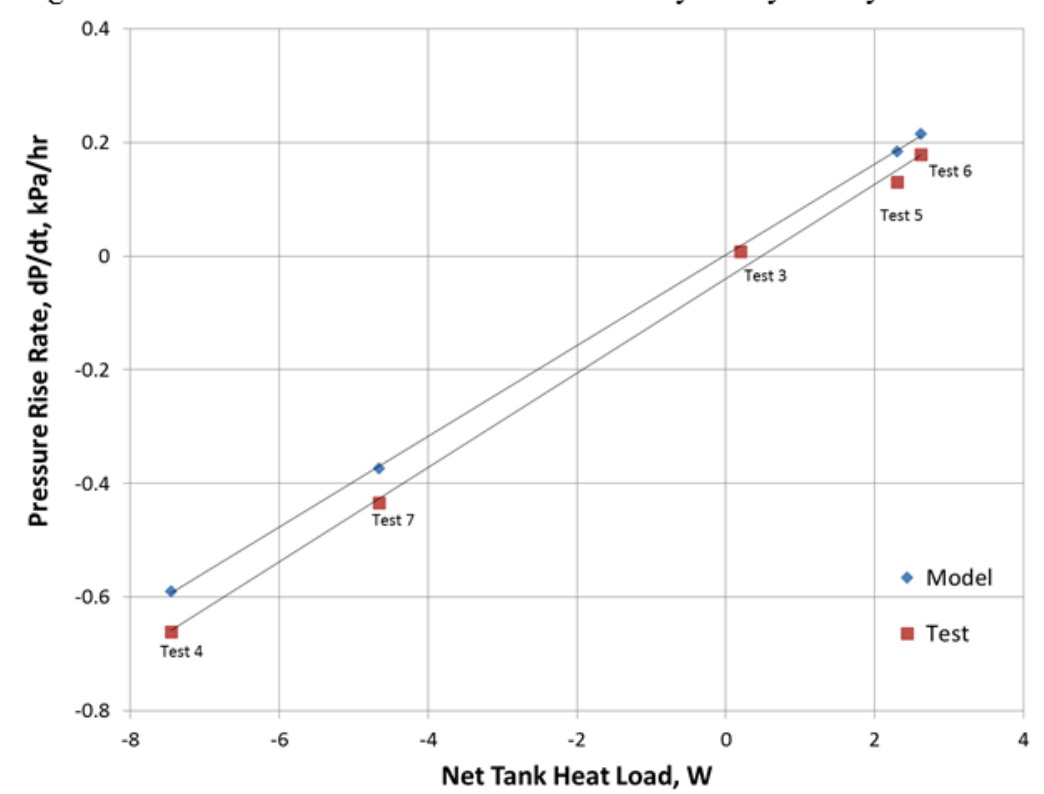

Figure 7. Tank pressurization sensitivity to net tank heat.

at the steady state ZBO setting, the same temperature gradient was just $3.8 \mathrm{~K}$. In that test, the distributed cooling fluid (in the cryocooler itself) temperature changed just $4.8 \mathrm{~K}$ from the cryocooler supply to the cooling loop to its return, while cooling the $7 \mathrm{~m}^{2}$ surface area tank. In addition, the cooling network's flow losses were low.

Finally, the test data was used as a basis to modify an integration model of the cryocooler, which was re-run to evaluate the projected performance of the RTBC system in the Scaling Study (Ref. 14). The test data served to validate the scaling study results.

Extension to NASA Missions 
Given the successful RBO and ZBO developments and the associated confirmation of the scaling study, NASA's interest's lies in further development of 20 and $90 \mathrm{~K}$ cryocoolers to meet the needs of NASA missions. The primary issue is to increase the lift rating of the cryocooler to meet the need for the large propellant tanks envisioned for flight. The customer for such an application is the Mars Study Capabilities Team, which is presently studying propulsion options for human missions to Mars. The following discussion covers cryocooler sizes or lifts, the heat lifted by the cryocooler, and the Mars mission need at this present state of study.

The main applications of ZBO for Mars missions include large, in-space chemical stages (Ref. 15), landers (Ref. 16), liquefaction of In-Situ Resource Utilization (ISRU) produced propellants (Ref. 17), and nuclear stages (Ref. 18). Current NASA architectures studies have been focused on the development of a single class of cryocooler for both temperatures. This minimizes development cost at the price of putting multiple cryocoolers on a stage and not taking advantage of possible mass and efficiency inputs that come with developing individual systems for each application.

The $90 \mathrm{~K}$ class cryocoolers (operations between $90 \mathrm{~K}$ and $120 \mathrm{~K}$, both oxygen and methane) are settling out in the $100-150 \mathrm{~W}$ lift range (Ref. 15, 16, and 17) This is based on worst case Mars surface heat loads just under $100 \mathrm{~W}$ per tank for the Mars Ascent Vehicle and Mars Descent stage. Current required ISRU production rates for oxygen are at just under $2.2 \mathrm{~kg} / \mathrm{hr}$, corresponding to a cryocooler lift of approximately $250 \mathrm{~W}$ (Ref. 18). For the $20 \mathrm{~K}$ application, the customer is the Nuclear Thermal Propulsion (NTP) team, which has not to date performed a structural-thermal optimization analysis, making it difficult to define a minimum lift requirement at $20 \mathrm{~K}$. Without a $90 \mathrm{~K}$ shield, a $8.4 \mathrm{~m}$ diameter $\mathrm{LH}_{2}$ tank heat leak will probably be in the hundreds of watts. With the addition of a $90 \mathrm{~K}$ shield, this could be reduced substantially, although it will require significantly more lift than the $250 \mathrm{~W}$ requirement for liquefaction.

\section{Cryocooler Developments}

Figure 8 shows that, while there are many flight cryocoolers available at 20 and $90 \mathrm{~K}$ (see Ref. 19), the largest has less than $1 \mathrm{~W}$ of cooling at $20 \mathrm{~K}$ and just $20 \mathrm{~W}$ at $90 \mathrm{~K}$. Given that there is considerable technology development and scaling required - over an order of magnitude increase in lift-- to achieve $\mathrm{LH}_{2} \mathrm{ZBO}$, NASA has invested in a $20 \mathrm{~K}-20 \mathrm{~W}$ reverse Brayton cryocooler development with Creare as a stepping stone to flight $\mathrm{LH}_{2} \mathrm{ZBO}$. Additionally, NASA has begun investing in multiple options $150 \mathrm{~W}$ at $90 \mathrm{~K}$ cryocooler to meet the $\mathrm{LOX}$ and $\mathrm{LCH}_{4}$ requirements.

\section{K-20W Cryocooler}

The two main technology developments of the $20 \mathrm{~K}-20 \mathrm{~W}$ cryocooler project are the compressor and recuperator technology. The required heat transfer in the recuperator is an order of magnitude greater than prior space cryocoolers developed to cool instruments. Scaling up existing space technology is cost prohibitive and commercial technology is too heavy and not suitable for operation in space. The baseline concept is a shell and tube heat exchanger using micro-tubes. The use of micro-tubes offers significant mass savings over commercial shell and tube technology as a large amount of surface area (and, by extension, a large amount of heat transfer) can be packaged within a small volume and higher heat transfer coefficients can be achieved. A challenge with this development is the welding of the micro-tubes to the tube support sheets, as leaks into the shell significantly degrade performance. The recuperator developed has 5 modules plumbed in series. Each module utilizes 6600 tubes of $0.559 \mathrm{~mm}$ 


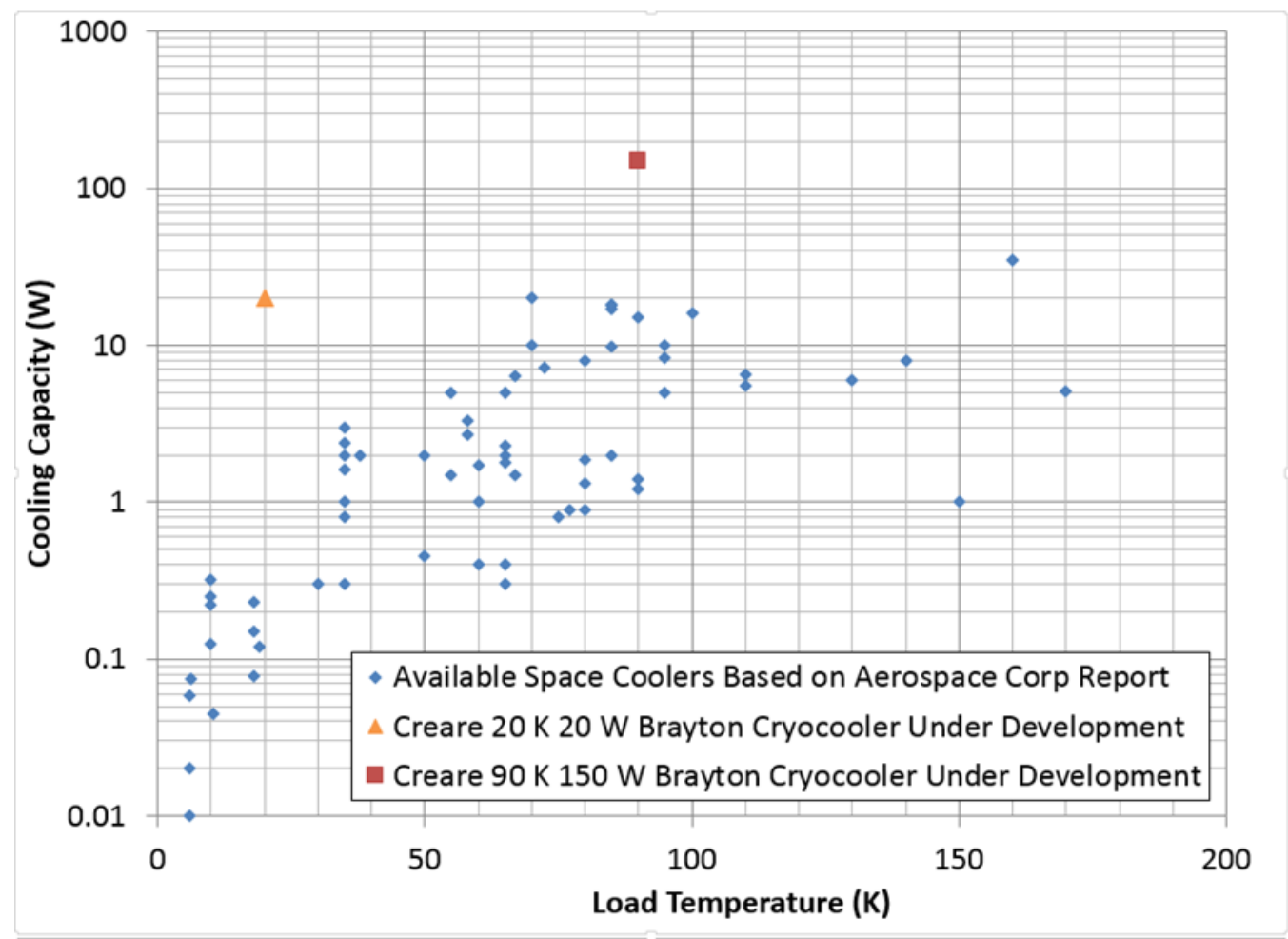

Figure 8. The available space cryocoolers lack the required capacity to meet the present NASA Mars mission concept requirements.

diameter. The primary technical challenge of $100 \%$ hermetic joints was achieved on all modules.

Additional technology development work was required on the compressor. The previous generation induction motor compressors had efficiencies of $40 \%$. The new compressor design has a three stage permanent magnet motor configuration with after-coolers at each stage. A single piece impeller and shaft construction was implemented to reduce risk of imbalance at high speeds. Also, a modified housing design with low pressure drop and an improved aerodynamic design of the inlet and outlet was implemented to accommodate the high volumetric flow rate. The technology goal of achieving $60 \%$ net efficiency for each compressor was achieved, resulting in a $33 \%$ reduction in input power relative to legacy technology. This $20 \mathrm{~K}-20 \mathrm{~W}$ cooler is shown in Figure 9.

There are additional tasks for this cryocooler beyond what is planned. An independent verification test, with a longer test series that varies flow impedances and heat rejection temperatures is important to ensure robust performance over a broad range of likely tank sizes 


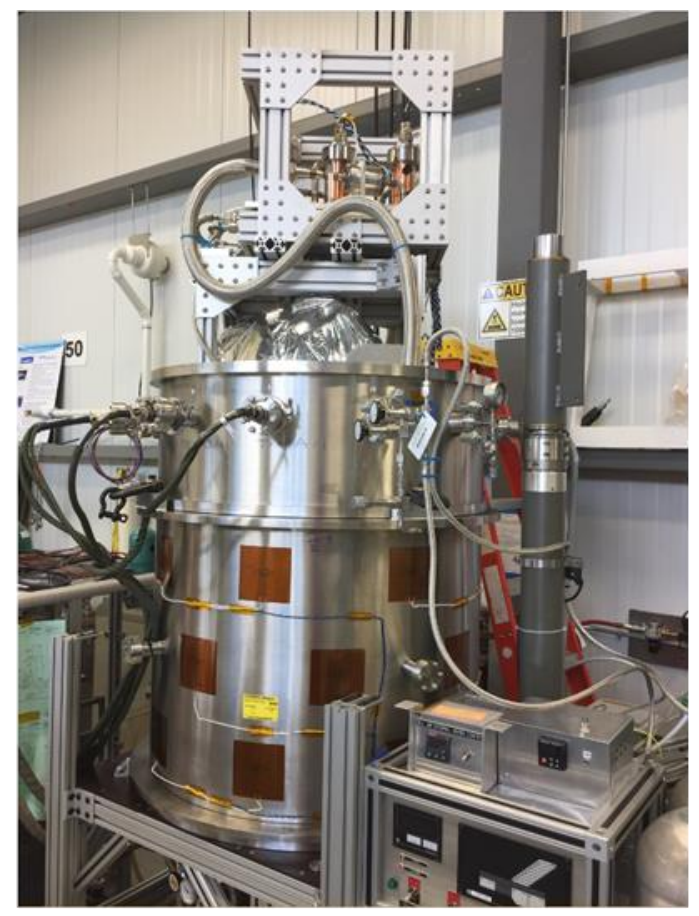

Figure 9. The assembled $20 \mathrm{~K}-20 \mathrm{~W}$ cryocooler installed into the bottom section of the vacuum bell jar, in preparation for testing.

and temperatures in space. Also, of the flight qualification tasks of this cryocooler, the greatest need is the vibration test. While the cryocooler was designed for launch vibration, the extensive weld development work on the recuperator, with over 6000 tubes in each of the five modules, requires representative flight vibration testing to ensure the assembly and welding works as designed.

\section{K- 150W Cryocooler}

There are two separate funded developments for $150 \mathrm{~W}$ at $90 \mathrm{~K}$ cryocoolers. The $90 \mathrm{~K}-150 \mathrm{~W}$ developments are part of a new effort intended to mature technologies for a high-capacity space cryocooler. One development is a Stirling cycle based cryocooler developed by Converter Source. This development is in its early stages and therefore not included here. The other development is a Brayton cycle being developed by Creare.

The initial focus of the Creare effort is on the compressor and compressor drive technologies, which represent the most significant departure from current space component technologies. The other key cryocooler components, the recuperator and turbo-alternator, are straightforward adaptations of existing technology. The recuperator leverages the development work from the $20 \mathrm{~K}-20 \mathrm{~W}$ program. Due to the higher operating temperature, only a single recuperator module is required, but this module comprises 18,000 tubes, a scale-up of three relative to the $20 \mathrm{~K}-20 \mathrm{~W}$ recuperators, due to the higher flow rates. The turbo-alternator is nearly identical to an existing compressor design with the primary design change being the aerodynamic features. The compressor and compressor drive are three times the capacity of the $20 \mathrm{~K}-20 \mathrm{~W}$ compressors which represent the highest capacity compressors built to date for a space

cryocooler. Preliminary designs of each have been developed and Creare is currently developing fabrication drawings for the compressor. 


\section{Related Developments}

The other aspect to promoting advanced chemical propulsion with cryogens is minimizing the heat leak. Minimizing the heat leak is critical to reducing the size of the cryocoolers, which has a multi-faceted impact on the missions. First, it reduces the mass, power, and lift requirement, critical parameters given the state-of-the-art in flight cryocoolers. Secondarily, the associated cost and volume of the cryocooler decreases.

Reducing heat leak for the NTP concept requires, first and foremost, a vehicle structural design that is driven both by the thermal and structural concerns. The $90 \mathrm{~K}$ cooling of this structure should also be considered within this configuration (Ref. 20). This will affect the location of the 90K cryocooler, a key consideration to minimizing cryocooler parasitic heat.

Depending on the vehicle heat load, a much larger $20 \mathrm{~K}$ cryocooler may be required. If the vehicle structure must be aluminum, the heat leak could be well over a $1000 \mathrm{~W}$, according to preliminary in-house analysis. This would require a much larger cryocooler that would be much more expensive. It could be that this level of heat and associated power would be impractical for the NTP mission.

Besides the thermally optimized structure, layouts to determine appropriate fill, drain, vent, and feed line lengths, diameter, and location need to be considered for the NTP $\mathrm{LH}_{2}$ stage and for $\mathrm{LO}_{2} / \mathrm{LCH}_{4}$ stages. A routing of the lines needs to be determined to be able to understand and minimize the heat leak to the fluid and if, where, and how intermediate cooling $(90 \mathrm{~K})$ could be located. Since the heat load into the lines will include both conduction from the engine and radiation from the engine and environment, the heat load will not be directly proportional to length.

It is also recommended that the heat load of a liquid hydrogen tank be tested with the integrated $\mathrm{LH}_{2}$ cryocooler. It would be more efficient and flight-like with the addition of a broad area cooled shield coupled to a $90 \mathrm{~K}$ cryocooler, perhaps the one under development. This twostage configuration would provide $\mathrm{LH}_{2}$ tank pressure control insight with the thermal control of both cryocoolers.

\section{Summary}

In order to efficiently meet the mission requirements for a human flight to Mars with cryogenic propulsion, it is essential to have zero boil-off storage meet the long loiter periods anticipated. The history of the ZBO concept has been shown to aide in the understanding of the importance of distributed cooling, which substantially minimizes the thermal gradients and allows for robust pressure control. To further this end, NASA is investing in flight cryocooler technologies to advance the state-of-the-art in $\mathrm{LH}_{2}$ cryocoolers $(20 \mathrm{~K})$ and in large $\mathrm{LO}_{2} / \mathrm{LCH}_{4}(90 \mathrm{~K})$ cryocoolers. Additionally, NASA is pursuing developments to reduce the heat leaks into cryogenic tanks.

Funding: This effort was funded by NASA's Game Changing Technology Development Program.

\section{References}

1. Polsgrove, Tara, et. al., "Mars Ascent Vehicle Design for Human Exploration," AIAA 2015-4416, AIAA Space Forum. 
2. Plachta, David W.: Hybrid Thermal Control Testing of a Cryogenic Propellant Tank. NASA/TM-1999-209389, 1999. http://ntrs.nasa.gov

3. Heydayat, Ali, et al.: Large Scale Demonstration of Liquid Hydrogen Storage With Zero Boiloff. AIP Conf. Proc., vol. 613, 2002, p. 1276.

4. Plachta, David: Results of an Advanced Development Zero Boil-Off Cryogenic Propellant Test. NASA/TM-2004-213390 (AIAA-2004-3837), 2004. http://ntrs.nasa.gov

5. Plachta, David W., et.al..: Cryogenic Boil-Off Reduction System, Advances in Cryogenic Engineering, vol. 53B, 2008, pp. 1457-1466.

6. Feller, J., et al.: Analysis of Continuous Heat Exchangers for Cryogenic Boil-Off Reduction. Adv. Cryog. Eng., vol. 53, 2008, p. 401.

7. Feller, J.R., et al.: Characterization of an Actively Cooled Metal Foil Thermal Radiation Shield. AIP Conf. Proc., vol. 1218, 2010, pp. 1187-1194.

8. Feller, J.R., et al.: Demonstration of a Cryogenic Boil-Off Reduction System Employing an Actively Cooled Thermal Radiation Shield. Kluwer Academic/Plenum Publishers, New York, NY, 2010, p. 601.

9. Christie, R.J., et al.: Broad Area Cooler Concepts for Cryogenic Propellant Tanks. Thermal \& Fluids Analysis Workshop, Hampton, VA, 2011.

10. Plachta, D.W.; Johnson, W.L.; and Feller, J.R.: Cryogenic Boil-Off Reduction System Testing. Presented at the 50th AIAA/ASME/SAE/ASEE Joint Propulsion Conference, Cleveland, OH, 2014.

11. Plachta, D.W.; Johnson, W.L.; and Feller, J.R. Zero Boil-Off System Testing, Cryogenics 74, pp. 88-94, 2016, Elsevier, Ltd., http://www.sciencedirect.com/science/article/pii/S0011227515001265

12. Plachta, D.W.; Johnson, W.L.; and Feller, J.R.: Liquid Nitrogen Zero Boil-Off Testing. NASA/TP_-2017-219389.

13. NASA CR-134477, Keller, C. W., Cunnington, G. R., and Glassford, A. P., Thermal Performance of Multilayer Insulations, Lockheed Missiles \& Space Company, April 1974.

14. Plachta, D, Guzik, M., Cryogenic Boil-Off Reduction System Scaling Study, Cryogenics Volume 60, pages 62-67, 2014, www.elsevier.com/locate/cryogenics

15. Percy, T, et.al., "Design and Development of a Methane Cryogenic Propulsion Stage for Human Mars Exploration", AIAA SPACE 2016, AIAA SPACE Forum, (AIAA 20165492). https://doi.org/10.2514/6.2016-5492

16. Hauser, D, Johnson, W.J., "Liquefaction and Storage of In-Situ O2 on the Surface of Mars", 9th Symposium on Space Resource Utilization, AIAA SciTech Forum, (AIAA 2016-0721). https://doi.org/10.2514/6.2016-0721

17. Johnson, W.J., et.al., "Comparison of Oxygen Liquefaction Methods for Use on the Martian Surface," to be presented at 2017 Space Cryogenics Workshop, Oak Park, IL.

18. Taylor, B.D., et.al., "Cryogenic Fluid Management Technology Development for Nuclear Thermal Propulsion", 51st AIAA/SAE/ASEE Joint Propulsion Conference, AIAA Propulsion and Energy Forum, (AIAA 2015-3957). https://doi.org/10.2514/6.2015-3957

19. Cha, J.S., Yuan, S.W., "Space Cryocooler Vendor Survey Update: 2013," Aerospace Report No. TOR-2013(3905)-4

20. Plachta, D.W. et. al., In-Space Cryogenic Propellant Storage Application for a $20 \mathrm{~W}$ at 20K Cryocooler, Cryocoolers 19, pp. 557-566, ICC Press, 2016. 